\title{
Protective Effects of Lactobacillus plantarum CCFM8610 against Acute Cadmium Toxicity in Mice
}

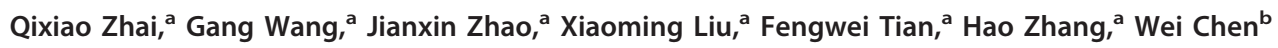 \\ School of Food Science and Technology, Jiangnan University, Wuxi, China ${ }^{a}$; State Key Laboratory of Food Science and Technology, Jiangnan University, Wuxi, China ${ }^{b}$
}

This study evaluated the protective effects of Lactobacillus plantarum CCFM8610, a selected probiotic with good cadmium binding capacity, against acute cadmium toxicity in mice. Ninety mice were divided into prevention and therapy groups. In the prevention groups, CCFM8610 was administered at $10^{9} \mathrm{CFU}$ once daily for 7 days, followed by a single oral dose of cadmium chloride at $1.8 \mathrm{mg}$ cadmium for each mouse. In the therapy groups, the same dose of CCFM8610 was administered for 2 days after an identical single dose of cadmium exposure. Mice that received neither cadmium nor culture or that received cadmium alone served as negative and positive controls, respectively. The effects of both living and dead CCFM8610 on cadmium ion concentrations in feces, liver, and kidney were determined. Moreover, the alterations in reduced glutathione (GSH), malondialdehyde (MDA), superoxide dismutase (SOD), catalase (CAT), and histopathology in the liver and kidney were investigated. The results showed that compared to the mice that received cadmium only, CCFM8610 treatment can effectively decrease intestinal cadmium absorption, reduce tissue cadmium accumulation, alleviate renal and hepatic oxidative stress, and ameliorate hepatic histopathological changes. Living CCFM8610 administered after cadmium exposure offered the most significant protection. Our results suggested that CCFM8610 is more effective against acute cadmium toxicity than a simple antioxidant treatment due to its special physiological functions and that it can be considered a new dietary therapeutic strategy against acute cadmium toxicity.

admium (Cd) is an ubiquitous environmental pollutant that causes a variety of adverse effects in both humans and animals. For the general population, food and tobacco smoking are the main sources of cadmium exposure due to the increased cadmium uptake by crops (1). With industrial development, people can also be exposed to cadmium through fume inhalation, paint pigments, cadmium-nickel batteries, electroplating, and fertilizers $(2,3)$. In China, several severe cadmium pollution incidents have been reported in Hunan and Guangxi Provinces in recent years, causing great public health concerns.

Cadmium accumulates mainly in the kidney and liver; these two organs are critical targets for acute cadmium toxicity (4-6). Previous studies have found that the mechanisms of cadmium toxicity involve depletion of reduced glutathione (GSH), inhibition of antioxidant enzymes, and enhanced production of reactive oxygen species (ROS) $(7,8)$. This abnormal level of ROS in turn induces increased lipid peroxidation and oxidative DNA damage (9).

Acute cadmium poisoning causes nausea, vomiting, testicular injury, renal damage, and hepatic necrosis (4). The most direct way to alleviate acute cadmium intoxication is to promote cadmium excretion by chelation therapy. However, in addition to unavoidable side effects like renal toxicity, chelators such as dithiocarbamates and monoisoamyl meso-2,3-dimercaptosuccinate (MiADMS) are effective only if given a short time after cadmium exposure $(10,11)$ and cannot alleviate the oxidative stress in the liver or brain (12). Another therapeutic possibility is to alleviate cadmium-induced oxidative stress using antioxidants, but several of them, including melatonin and $\alpha$-lipoic acid, failed to reduce the cadmium burden in animal tissues $(13,14)$.

Recently, some phytochemicals and plant extracts with antioxidative properties have been found to have the capacity to decrease tissue cadmium levels and cadmium-induced oxidative stress (15-18). Such natural compounds have few side effects, and some of them can be served as dietary nutritional ingredients. The positive correlation between dietary supplements and the intervention or prevention of cadmium toxicity found in these studies led us to seek other dietary supplements which are more commonly used in daily life.

Previous reports have revealed that some lactobacilli, including Lactobacillus rhamnosus, L. plantarum, and L. brevis, can bind and remove heavy metals such as cadmium, lead, and copper in vitro $(19,20)$. Besides the cadmium binding capacity, lactobacilli are also known to have antioxidative properties in human subjects, which may be another important characteristic for cadmium toxicity protection (21-23). On the basis of these special functions, lactobacilli seem to have potency against cadmium toxicity. This hypothesis was also proposed in a recent review (24), but to our knowledge, very few studies on the protective effects of lactobacilli against cadmium toxicity have been carried out so far, and the mechanism of such protection has not been studied yet. Therefore, it is interesting to investigate whether some lactobacilli might play a role in the alleviation of acute cadmium toxicity.

In this study, we selected a lactobacillus with good cadmium binding ability and evaluated its protective effects against acute oral cadmium exposure in the kidney and liver of mice. Changes in cadmium ion concentrations in feces, liver, and kidney were determined. The alterations of GSH, malondialdehyde (MDA), superoxide dismutase (SOD), catalase (CAT), and histopathology

Received 6 November 2012 Accepted 14 December 2012

Published ahead of print 21 December 2012

Address correspondence to Wei Chen, chenwei66@jiangnan.edu.cn, or

Fengwei Tian, fwtian@jiangnan.edu.cn.

Supplemental material for this article may be found at http://dx.doi.org/10.1128 /AEM.03417-12

Copyright $\odot$ 2013, American Society for Microbiology. All Rights Reserved. doi:10.1128/AEM.03417-12 
in the liver and kidney were investigated. Some possible protective mechanisms of lactobacilli are also proposed.

\section{MATERIALS AND METHODS}

Chemicals and reagents. Kits used to measure the levels of MDA and GSH and the activities of SOD and CAT were purchased from the Jiancheng Bioengineering Institute (Nanjing, China). Cadmium chloride and other analytical laboratory chemicals and reagents were purchased from Sinopharm Chemical Reagent Company (Shanghai, China).

Bacterial strains and culture. L. rhamnosus GG (ATCC 533103) was purchased from ATCC. Bifidobacterium bifidum (CCFM8622), L. plantarum (CCFM8610, CCFM8614, CCFM8661), L. reuteri (CCFM8761), L. bulgaricus (CCFM8004), L. gasseri (CCFM8602), and L. delbrueckii (CCFM8147) were obtained from the Culture Collections of Food Microbiology, Jiangnan University (Wuxi, China). All strains were cultured in de Man, Rogosa, and Sharpe (MRS) broth (Hopebio Company, Qingdao, China) at $37^{\circ} \mathrm{C}$ for $18 \mathrm{~h}$.

To obtain both living and dead biomass for the animal experiments, the cultured biomass was washed twice with ultrapure water and divided equally into two parts. One part was lyophilized directly with skimmed milk as its protectant and stored at $-20^{\circ} \mathrm{C}$ as a living biomass. Another part was boiled at $100^{\circ} \mathrm{C}$ for $60 \mathrm{~min}$ before lyophilization to obtain dead biomass. Colony counting was conducted before the animal experiments to ensure the survival of bacteria in the preparations for animal treatment.

Cadmium binding experiments. To select the strain to use in the animal study, the binding abilities of both living and dead strains were investigated. Nine strains were incubated for $18 \mathrm{~h}$, and each cultured biomass was divided equally into two parts. One part was dried at $80^{\circ} \mathrm{C}$ for $24 \mathrm{~h}$ to obtain the dry weight of the biomass. The other part of the biomass was centrifuged at $8,000 \times g$ for 20 min to obtain the living cell pellets or was boiled at $100^{\circ} \mathrm{C}$ for $60 \mathrm{~min}$ before centrifugation to obtain the dead cell pellets. A weighed amount of both living and dead cell pellets was resuspended in ultrapure water containing $5 \mathrm{mg} /$ liter cadmium ion to give a final bacterial concentration of $1 \mathrm{~g} /$ liter on a dry weight basis. The concentration of cadmium was selected to fit the intestinal cadmium concentration in cadmium-exposed mice, based on the cadmium dose used in animal experiments. Then, the $\mathrm{pH}$ of the suspension was immediately set to 6 using diluted $\mathrm{NaOH}$ or $\mathrm{HNO}_{3}$, and the samples were incubated for 1 $\mathrm{h}$ at $28^{\circ} \mathrm{C}(19,25)$. After the incubation, the suspension was centrifuged at $8,000 \times g$ for $20 \mathrm{~min}$ and a sample was taken from the supernatant for the analysis of residual cadmium contents. For detecting the cadmium concentration of strains, cell pellets were incubated in the cadmium-free ultrapure water instead of the cadmium solution. After centrifugation, cell pellets were collected and digested in concentrated $\mathrm{HNO}_{3}$ with a microwave digestion system for the analysis of cadmium contents. The exact cadmium binding capacities of strains were expressed with the exclusion of the cadmium concentration of the strains themselves. The cadmium concentration was measured by flame atomic absorption spectrophotometry (Spectr AA 220; Varian). All the assays were conducted in triplicate, and average values were used for data analysis.

Animal experiments. (i) Animals and experimental design. Adult male Kunming mice obtained from the Shanghai Laboratory Animal Center (Shanghai, China) were used in the experiments. The mice were selected strictly by weight (between 28 and $30 \mathrm{~g}$ ) and kept in stainless steel cages in a temperature- and humidity-controlled room that was equipped to maintain a 12-h light/12-h dark cycle. The mice were fed standard commercial rat chow, and water was given ad libitum. All the protocols of the study were approved by the Ethics Committee of Jiangnan University, China (JN no. 4 2012). All the procedures of the study were carried out in accordance with European Community guidelines (Directive 2010/63/ EU) for the care and use of experimental animals.

As shown in Table 1, the mice were randomly divided into two major groups. Prevention groups were used to investigate the effects of the oral administration of lactobacilli before cadmium exposure. Therapy groups were set to investigate the therapeutic efficacy of lactobacilli after acute
TABLE 1 Animal experimental protocol ${ }^{a}$

\begin{tabular}{|c|c|c|c|c|}
\hline \multirow[b]{3}{*}{ Group } & \multicolumn{4}{|c|}{ Treatment on the indicated day(s) for the following: } \\
\hline & \multicolumn{2}{|c|}{ Prevention groups } & \multicolumn{2}{|c|}{ Therapy groups } \\
\hline & $1-7$ & 8 & 1 & $1-2$ \\
\hline Control $(n=10)$ & SM & PW & PW & SM \\
\hline Cd only $(n=15)$ & SM & $\mathrm{Cd}$ & $\mathrm{Cd}$ & SM \\
\hline $\begin{array}{l}\mathrm{Cd}+\text { living } 8610 \\
\quad(n=10)\end{array}$ & $\begin{array}{l}\text { SM + living } \\
8610\end{array}$ & $\mathrm{Cd}$ & $\mathrm{Cd}$ & $\begin{array}{l}\text { SM + living } \\
8610\end{array}$ \\
\hline $\begin{array}{l}\mathrm{Cd}+\text { dead } 8610 \\
\quad(n=10)\end{array}$ & $\begin{array}{l}\text { SM + dead } \\
8610\end{array}$ & $\mathrm{Cd}$ & $\mathrm{Cd}$ & $\begin{array}{c}\text { SM + dead } \\
8610\end{array}$ \\
\hline
\end{tabular}

${ }^{a} \mathrm{PW}$, a single oral dose of $0.5 \mathrm{ml}$ plain water; $\mathrm{SM}$, a single oral dose of $0.5 \mathrm{ml}$ skim milk; Cd, a single oral dose of cadmium chloride in $0.5 \mathrm{ml}$ plain water at $1.8 \mathrm{mg} \mathrm{Cd}$ each mouse; SM + living 8610, living L. plantarum CCFM8610 at $1 \times 10^{9} \mathrm{CFU}$ with 0.5 $\mathrm{ml}$ skim milk once daily; SM + dead 8610, dead L. plantarum CCFM8610 with $0.5 \mathrm{ml}$ skim milk once daily. Animals received plain water, skim milk, Cd, and CCFM8610 via gavage. Mice were fasted for $12 \mathrm{~h}$ before cadmium exposure. In the therapy groups, skim milk and lactobacilli were administered $1 \mathrm{~h}$ after cadmium exposure.

cadmium exposure. In both prevention and therapy groups, mice were divided into four subgroups: a control group (no cadmium or CCFM8610), a cadmium-only group, a cadmium plus living CCFM8610 group, and a cadmium plus dead CCFM8610 group. Skim milk served as a vehicle for the lactobacilli. On the basis of previous studies, the oral dose of $530 \mu \mathrm{mol}(60 \mathrm{mg}) \mathrm{Cd} / \mathrm{kg}$ of body weight appeared to be toxic to a variety of organs in mice, but the mortality was quite low (26-28). Therefore, this dose was selected in the present study. As the body weight of all animals remained at $30 \pm 2 \mathrm{~g}$ before cadmium exposure, each of them was administered an equal dose of $1.8 \mathrm{mg}$ cadmium for analysis of the cadmium concentration in feces. To serve as a comparative control, living $L$. bulgaricus CCFM8004 was applied in the therapy groups with methods identical to those used for CCFM8610 treatment.

At $4 \mathrm{~h}, 8 \mathrm{~h}, 12 \mathrm{~h}, 24 \mathrm{~h}$, and $48 \mathrm{~h}$ after cadmium exposure, each surviving mouse was put into a clean and empty cage for $15 \mathrm{~min}$, and fecal samples were collected. All mice were sacrificed under light ether anesthesia after the final feces collection. Livers and kidneys were excised, cleaned, and stored at $-80^{\circ} \mathrm{C}$ until the biochemical assays and cadmium estimation.

(ii) Determination of cadmium in tissues and feces. Samples were digested in concentrated $\mathrm{HNO}_{3}$ using a microwave digestion system. The cadmium concentration in the livers, kidneys, and feces was determined by a flame or graphite furnace atomic absorption spectrophotometer (Spectr AAS or AA; Varian). The cadmium contents were expressed in $\mu \mathrm{g} / \mathrm{g}$ of tissue wet weight and $\mathrm{mg} / \mathrm{g}$ of feces wet weight.

(iii) Determination of MDA, GSH, SOD, and CAT. The levels of MDA and GSH and the activities of SOD and CAT were measured according to the recommendations of the manufacturer, using an assay kit purchased from the Jiancheng Bioengineering Institute (Nanjing, China).

(iv) Histopathological studies. Livers and kidneys were fixed for $48 \mathrm{~h}$ in $10 \%$ formalin saline. Tissues were embedded in paraffin and sectioned at $5-\mu \mathrm{m}$ thickness using a rotary microtome. Sections were stained with hematoxylin-eosin (H\&E) for light microscopy examination. The results of histopathological studies were analyzed with a semistatistical evaluation. The frequency of tissue damage was indicated using the following symbols: - , no change was observed in the samples of all the animals of the studied group; +, changes were rarely observed in the samples of all the animals of the studied group (average, 1 to 2 changes per vision field); ++ , changes were occasionally observed in the samples of all the animals of the studied group (average, 8 to 10 changes per vision field); +++ , changes were often observed in the samples of all the animals of the studied group ( $>20$ changes per vision field).

Statistical analysis. Data were expressed as the mean \pm standard error of the mean (SEM) for each group. Differences between groups were analyzed using one-way analysis of variance (ANOVA), followed by the Tukey post hoc test. A $P$ value of $<0.05$ was considered to be statistically significant. 


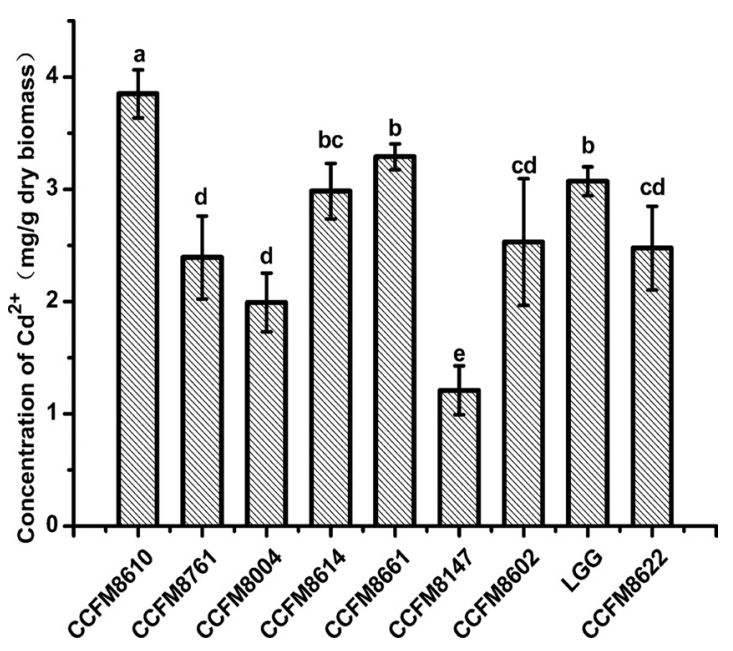

FIG 1 Cadmium binding abilities of living strains. The average of three replicates and standard deviation are presented. CCFM8610, CCFM8614, and CCFM8661 are Lactobacillus plantarum. CCFM8761 is L. reuteri. CCFM8004 is L. bulgaricus. CCFM8602 is L. gasseri. LGG is L. rhamnosus GG. CCFM8622 is Bifidobacterium bifidum. CCFM8147 is L. delbrueckii. Significant differences $(P<0.05)$ between the strains are indicated with different letters $(\mathrm{a}, \mathrm{b}, \mathrm{c}, \mathrm{d})$ above the bars.

\section{RESULTS}

Cadmium binding experiments. The cadmium binding abilities of the nine strains are shown in Fig. 1 and 2 for living and dead strains, respectively. Boiling treatment caused some alterations of binding capacities, but $L$. plantarum CCFM8610 had the highest biosorption levels in both living (3.851 $\pm 0.19 \mathrm{mg} / \mathrm{g}$ dry biomass) and dead ( $3.667 \pm 0.27 \mathrm{mg} / \mathrm{g}$ dry biomass) bacterial experiments. The levels of cadmium removal were $77 \%$ and $73 \%$ for living and dead CCFM8610, respectively. This led to a hypothesis that CCFM8610 might alleviate cadmium toxicity in vivo due to its good cadmium binding capacity, so CCFM8610 was selected for

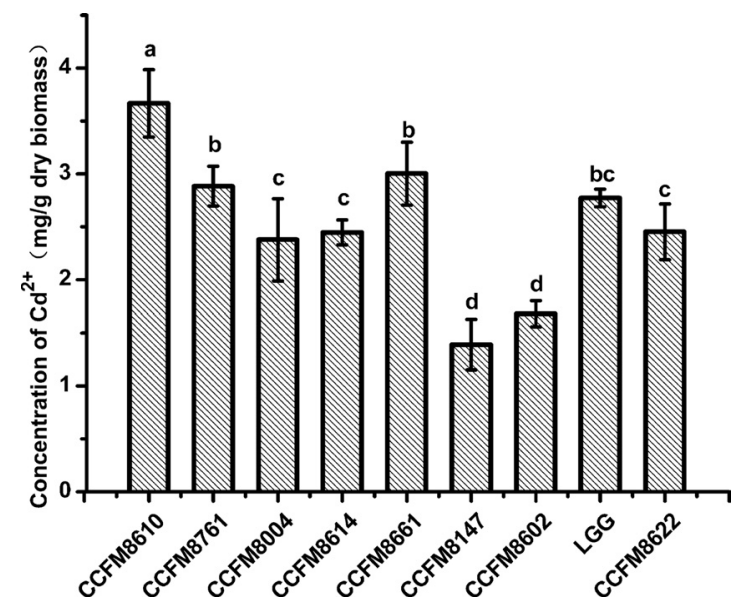

FIG 2 Cadmium binding abilities of dead strains. The average of three replicates and standard deviation are presented. CCFM8610, CCFM8614, and CCFM8661 are Lactobacillus plantarum. CCFM8761 is L. reuteri. CCFM8004 is L. bulgaricus. CCFM8602 is L. gasseri. LGG is L. rhamnosus GG. CCFM8622 is Bifidobacterium bifidum. CCFM8147 is L. delbrueckii. Significant differences $(P<0.05)$ between the strains are indicated with different letters $(\mathrm{a}, \mathrm{b}, \mathrm{c}, \mathrm{d})$ above the bars.

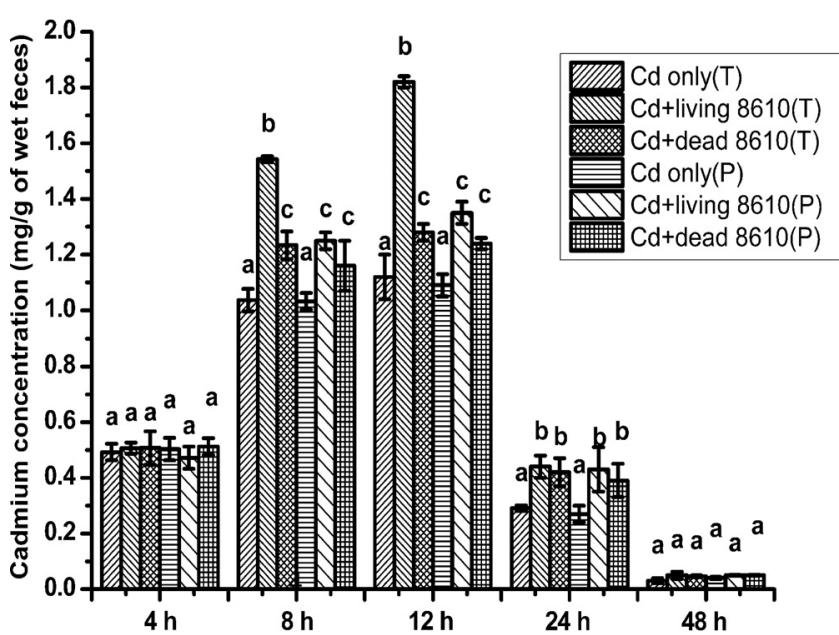

FIG 3 Effects of CCFM8610 treatments on levels of cadmium in the feces of mice at different times. Values are mean \pm SEM values with 10 mice in each group, except for 11 in the Cd-only (T) group, 12 in the Cd-only (P) group, and 9 in the Cd plus dead CCFM8610 (P) group. The letters a, b, and c mean that in each period, groups with different letters differ significantly $(P<0.05)$. $\mathrm{T}$, therapy groups; P, prevention groups; 8610, L. plantarum CCFM8610.

further animal study. A commercial yogurt starter culture, CCFM8004, with a cadmium binding capacity poorer than that of CCFM8610 was used in the animal study for comparison.

Animal experiments. (i) Mortality and physiological situation. The mortalities of mice in the Cd-treated therapy group and the Cd-treated prevention group were $4 / 15$ and 3/15 mice, respectively, $48 \mathrm{~h}$ after each mouse was administered a single oral dose of cadmium chloride at $1.8 \mathrm{mg} \mathrm{Cd}$. No death was found in the CCFM8610-treated groups, except for one in the Cd plus dead CCFM8610 prevention group. The mortality of mice in the Cd plus living CCFM8004 therapy group was 2/10 mice (see Table S1 in the supplemental material). Mice in the Cd-treated groups showed signs of constipation, and only small amounts of feces could be collected (no more than $0.05 \mathrm{~g}$ wet feces could be collected for each mouse at $15 \mathrm{~min}$ ). Such signs were ameliorated in mice treated with CCFM8610 (more than $0.15 \mathrm{~g}$ wet feces could be collected for each mouse in therapy groups treated with living CCFM8610 at $15 \mathrm{~min}$, and the amount almost reached the feces amount of control mice).

(ii) Cadmium concentration in feces, liver, and kidney. The alterations in cadmium levels in feces are represented in Fig. 3. Fecal cadmium concentrations in the control groups were too low to detect, so these data were not included in Fig. 3. The cadmium concentration increased in the first $12 \mathrm{~h}$ after oral exposure and decreased to a low level at $48 \mathrm{~h}$. Compared to the Cd-treated groups, both living and dead CCFM8610 treatments significantly increased fecal cadmium levels at $8 \mathrm{~h}, 12 \mathrm{~h}$, and $24 \mathrm{~h}(P<0.05)$. At $8 \mathrm{~h}$ and $12 \mathrm{~h}$, the levels were significantly higher in the therapy group with living CCFM8610 treatment than in the other treatment groups $(P<0.05)$. The fecal cadmium levels of mice in the Cd plus living CCFM8004 therapy group were significantly lower than those in the Cd plus living CCFM8610 therapy group (see Fig. S2 in the supplemental material).

Cadmium levels in the liver and kidney were significantly increased after Cd exposure (Fig. 4). Both living and dead CCFM8610 treatments significantly decreased cadmium levels. 


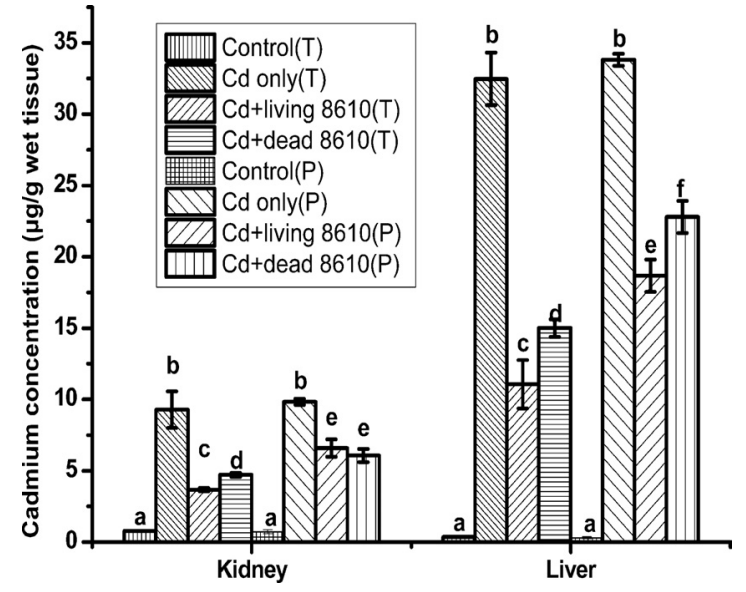

FIG 4 Effects of CCFM8610 treatments on levels of cadmium in the tissues of mice. Values are mean \pm SEM values with 10 mice in each group, except for 11 in the Cd-only (T) group, 12 in the Cd-only (P) group, and 9 in the $\mathrm{Cd}$ plus dead $8610(\mathrm{P})$ group. The letters $\mathrm{a}, \mathrm{b}, \mathrm{c}, \mathrm{d}, \mathrm{e}$, and $\mathrm{f}$ mean that in each tissue, groups with different letters differ significantly $(P<0.05)$. T, therapy groups; $\mathrm{P}$, prevention groups; 8610, L. plantarum CCFM8610.

Among these groups, living CCFM8610 treatment in the therapy groups showed the best protection against cadmium accumulation in the liver and kidney $(P<0.05)$. The decreasing cadmium levels in kidney and liver by living CCFM8004 treatment was not as significant as that by living CCFM8610 treatment (see Fig. S3 in the supplemental material).

(iii) MDA, GSH, SOD, and CAT in liver and kidney. In the kidney (Table 2), MDA levels were significantly increased in both the prevention and therapy Cd-treated groups and were accompanied by a marked decrease in the levels of GSH and in the activities of SOD and CAT $(P<0.05)$. Both living and dead L. plantarum CCFM8610 treatments had significant reversal effects on the alterations of SOD, GSH, and MDA. The SOD levels in the therapy groups with living CCFM8610 treatment were significantly higher than those in the other CCFM8610-treated groups. Only living CCFM8610 treatment in therapy groups increased the CAT activities compared to those in the Cd-treated group $(P<0.05)$.

In the liver (Table 3 ), acute cadmium intoxication also caused a marked increase of MDA and a decrease of GSH, SOD, and CAT. Both living and dead L. plantarum CCFM8610 treatments had significant protective effects on CAT, SOD, GSH, and MDA. Liv- ing CCFM8610 treatment in therapy groups significantly decreased the MDA levels compared to those in the other CCFM8610-treated groups $(P<0.05)$.

(iv) Histopathological studies. Acute cadmium exposure caused significant damage to the liver, including loss of intact liver plates, chromatin condensation, cytoplasmic vacuolization, and necrosis of hepatocytes. Living CCFM8610 treatment in the therapy groups significantly alleviated such hepatic injury, whereas the histological changes in the other CCFM8610-treated groups were not so evident (Table 4). Living CCFM8004 treatment in the therapy groups was not able to alleviate hepatic injury (see Fig. S4 in the supplemental material). However, no serious tissue damage in the kidney was observed in any group (Table 5). This may be because the dose of cadmium administered in our study (530 $\mu \mathrm{mol} \mathrm{Cd} / \mathrm{kg}$ of body weight $)$ is much lower than that $(790 \mu \mathrm{mol}$ $\mathrm{Cd} / \mathrm{kg}$ of body weight) which could cause mild histological changes in kidney (26). Some representative hepatic photomicrographs of animals in the control therapy, Cd-only therapy, and Cd plus living CCFM8610 therapy groups are shown in Fig. 5.

\section{DISCUSSION}

This study may be the first to evaluate some of the protective mechanisms of the oral administration of lactobacilli against acute cadmium intoxication. The present study provides biological evidence that $L$. plantarum CCFM8610 can increase fecal cadmium excretion, decrease tissue cadmium accumulation, reduce lipid peroxidation, and reverse deficits in antioxidant defense systems to alleviate acute cadmium toxicity.

The intoxication processes induced by acute oral cadmium exposure are summarized in Fig. 6. After intestinal absorption, cadmium in the liver induces the synthesis of metallothionein (MT), a low-molecular-weight protein that has a high affinity for cadmium (29). The Cd-MT complex is then either stored in the liver or transported to the kidney via blood. When the amount of cadmium in the liver and kidney exceeds the binding capability of MT, the non-MT-bound cadmium ions can induce oxidative stress, which in turn causes damage to these tissues $(30,31)$.

Recently, a large number of studies have tried to alleviate acute cadmium toxicity by reversing oxidative stress; some chemosynthetic or natural antioxidants have proven to be effective. However, such therapeutic strategies function only after the cadmium has been distributed into the organs. Our study demonstrates that a selected lactobacillus can increase the fecal cadmium excretion in the $24 \mathrm{~h}$ after acute oral exposure (Fig. 3). This protective effect

TABLE 2 Effects of L. plantarum CCFM8610 on cadmium-induced alterations of the activities of SOD and CAT and the levels of GSH and MDA in the kidneys of mice ${ }^{a}$

\begin{tabular}{|c|c|c|c|c|}
\hline Group & $\begin{array}{l}\text { SOD activity } \\
\text { (U/mg protein) }\end{array}$ & $\begin{array}{l}\text { CAT activity } \\
\text { (U/mg protein) }\end{array}$ & $\begin{array}{l}\text { GSH level } \\
\text { (mg/g protein) }\end{array}$ & $\begin{array}{l}\text { MDA level } \\
\text { (nmol/g protein) }\end{array}$ \\
\hline Control (T) & $19.09 \pm 1.13^{\mathrm{a}}$ & $210.95 \pm 27.13^{\mathrm{a}}$ & $3.71 \pm 0.12^{\mathrm{a}}$ & $83.23 \pm 12.72^{\mathrm{a}}$ \\
\hline Cd only (T) & $10.25 \pm 0.56^{\mathrm{b}}$ & $149.73 \pm 31.49^{\mathrm{b}}$ & $1.43 \pm 0.09^{\mathrm{b}}$ & $262.26 \pm 21.31^{\mathrm{b}}$ \\
\hline $\mathrm{Cd}+$ living $8610(\mathrm{~T})$ & $16.34 \pm 1.38^{\mathrm{c}}$ & $177.75 \pm 11.52^{c}$ & $2.89 \pm 0.14^{\mathrm{c}}$ & $159.17 \pm 19.97^{\mathrm{c}}$ \\
\hline $\mathrm{Cd}+$ dead $8610(\mathrm{~T})$ & $14.21 \pm 0.82^{\mathrm{d}}$ & $159.20 \pm 21.74^{\mathrm{b}}$ & $2.62 \pm 0.26^{\mathrm{c}}$ & $163.28 \pm 13.41^{\mathrm{c}}$ \\
\hline Control (P) & $19.50 \pm 0.91^{\mathrm{a}}$ & $225.09 \pm 20.66^{\mathrm{a}}$ & $3.43 \pm 0.18^{\mathrm{a}}$ & $76.70 \pm 20.70^{\mathrm{a}}$ \\
\hline Cd only (P) & $8.81 \pm 0.42^{\mathrm{b}}$ & $128.13 \pm 37.08^{b}$ & $1.67 \pm 0.15^{\mathrm{b}}$ & $248.55 \pm 18.93^{b}$ \\
\hline $\mathrm{Cd}+$ living $8610(\mathrm{P})$ & $14.25 \pm 0.30^{\mathrm{d}}$ & $158.70 \pm 18.54^{\mathrm{b}}$ & $2.55 \pm 0.20^{c}$ & $170.24 \pm 18.24^{\mathrm{c}}$ \\
\hline $\mathrm{Cd}+$ dead $8610(\mathrm{P})$ & $13.57 \pm 0.97^{\mathrm{d}}$ & $156.82 \pm 13.44^{\mathrm{b}}$ & $2.39 \pm 0.23^{c}$ & $160.88 \pm 8.92^{\mathrm{c}}$ \\
\hline
\end{tabular}

${ }^{a}$ Values are mean \pm SEM values with 10 mice in each group, except for 11 in the Cd-only (T) group, 12 in the Cd-only (P) group, and 9 in the Cd + dead 8610 (P) group. The superscript letters a, b, c, and d indicate statistically significant differences at a $P$ value of $<0.05$ within each row comparison. T, therapy group; $\mathrm{P}$, prevention group; $8610, L$. plantarum CCFM8610. 
TABLE 3 Effects of L. plantarum CCFM8610 on cadmium-induced alterations of the activities of SOD and CAT and the levels of GSH and MDA in the livers of mice $^{a}$

\begin{tabular}{|c|c|c|c|c|}
\hline Group & $\begin{array}{l}\text { SOD activity } \\
\text { (U/mg protein) }\end{array}$ & $\begin{array}{l}\text { CAT activity } \\
\text { (U/mg protein) }\end{array}$ & $\begin{array}{l}\text { GSH level } \\
\text { (mg/g protein) }\end{array}$ & $\begin{array}{l}\text { MDA level } \\
\text { (nmol/g protein) }\end{array}$ \\
\hline Control (T) & $39.26 \pm 2.08^{\mathrm{a}}$ & $186.28 \pm 18.55^{\mathrm{a}}$ & $4.82 \pm 0.08^{\mathrm{a}}$ & $57.67 \pm 13.40^{\mathrm{a}}$ \\
\hline Cd only $(\mathrm{T})$ & $21.03 \pm 1.41^{\mathrm{b}}$ & $121.90 \pm 22.01^{\mathrm{b}}$ & $1.09 \pm 0.11^{\mathrm{b}}$ & $204.49 \pm 14.12^{\mathrm{b}}$ \\
\hline $\mathrm{Cd}+$ dead $8610(\mathrm{~T})$ & $30.85 \pm 2.35^{\mathrm{c}}$ & $156.30 \pm 29.23^{c}$ & $2.55 \pm 0.06^{\mathrm{c}}$ & $140.19 \pm 11.57^{\mathrm{d}}$ \\
\hline Control (P) & $40.71 \pm 1.85^{\mathrm{a}}$ & $195.78 \pm 15.91^{\mathrm{a}}$ & $4.31 \pm 0.15^{\mathrm{a}}$ & $56.22 \pm 18.89^{\mathrm{a}}$ \\
\hline Cd only $(\mathrm{P})$ & $22.74 \pm 1.33^{\mathrm{b}}$ & $113.52 \pm 13.19^{\mathrm{b}}$ & $1.87 \pm 0.07^{\mathrm{d}}$ & $213.06 \pm 16.88^{\mathrm{b}}$ \\
\hline
\end{tabular}

${ }^{a}$ Values are mean \pm SEM values with 10 mice in each group, except for 11 in the Cd-only $(\mathrm{T})$ group, 12 in the Cd-only $(\mathrm{P})$ group, and 9 in the Cd + dead $8610(\mathrm{P})$ group. The superscript letters a, b, c, and d indicate statistically significant differences at a $P$ value of $<0.05$ within each row comparison. T, therapy group; $\mathrm{P}$, prevention group; $8610, L$. plantarum CCFM8610.

may be more positive than a simple antioxidant treatment, as it decreases the intestinal absorption at an early phase of cadmium intoxication to prevent the transportation of a high level of this toxic metal into the human body. The decreased intestinal absorption of cadmium can reduce cadmium accumulation in tissues (Fig. 4) and then cause a reduction of the non-MT-bound cadmium ion level, which in turn alleviates oxidative stress.

The ability of L. plantarum CCFM8610 to decrease the intestinal absorption may be attributed to three aspects. First, the results of the cadmium binding experiments, shown in Fig. 1 and Fig. 2, demonstrate that both living and dead CCFM8610 can remove more than $70 \%$ of cadmium ion at a 5 -mg/liter initial cadmium concentration after a contact time of $1 \mathrm{~h}$, and the cadmium binding capacity of CCFM8610 is significantly higher than that of other tested strains $(P<0.05)$. So, its fast and effective binding ability enables CCFM8610 to bind cadmium ions before intestinal absorption and increase cadmium excretion since strains are excreted through feces (32). A similar protective mechanism was reported for L. rhamnosus GG, which can modulate intestinal aflatoxin $\mathrm{B}_{1}\left(\mathrm{AFB}_{1}\right)$ absorption in rats by increasing fecal $\mathrm{AFB}_{1}$ excretion (33). This conclusion is also confirmed by our animal study comparing CCFM8610 and CCFM8004. The protective effects of CCFM8610 are superior to those of CCFM8004, indicating

TABLE 4 Effects of L. plantarum CCFM8610 on cadmium-induced histopathological alterations in the liver of mice ${ }^{a}$

\begin{tabular}{|c|c|c|c|c|}
\hline \multirow[b]{2}{*}{ Group } & \multicolumn{4}{|c|}{ Score for the indicated symptom } \\
\hline & $\begin{array}{l}\text { Loss of intact } \\
\text { liver plates }\end{array}$ & $\begin{array}{l}\text { Chromatin } \\
\text { condensation }\end{array}$ & $\begin{array}{l}\text { Cytoplasmic } \\
\text { vacuolization }\end{array}$ & $\begin{array}{l}\text { Necrosis of } \\
\text { hepatocytes }\end{array}$ \\
\hline Control (T) & - & - & - & - \\
\hline Cd only (T) & +++ & +++ & +++ & ++ \\
\hline $\mathrm{Cd}+$ living $8610(\mathrm{~T})$ & + & + & & - \\
\hline $\mathrm{Cd}+$ dead $8610(\mathrm{~T})$ & ++ & ++ & +++ & + \\
\hline Control (P) & - & - & & - \\
\hline Cd only (P) & ++ & +++ & +++ & ++ \\
\hline $\mathrm{Cd}+$ living $8610(\mathrm{P})$ & ++ & ++ & & \\
\hline $\mathrm{Cd}+$ dead $8610(\mathrm{P})$ & ++ & ++ & +++ & + \\
\hline \multicolumn{5}{|c|}{$\begin{array}{l}\text { The histopathological analysis was done with } 10 \text { mice in each group, except for } 11 \text { in } \\
\text { the Cd-only (T) group, } 12 \text { in the Cd-only (P) group, and } 9 \text { in the Cd }+ \text { dead } 8610 \text { (P) } \\
\text { group. T, therapy group; P, prevention group; } 8610, \text { L plantarum CCFM8610; }- \text {, no } \\
\text { change was observed in the samples of all the animals of the studied group; }+ \text {, changes } \\
\text { were rarely observed in the samples of all the animals of the studied group (average, } 1 \text { to } \\
2 \text { changes per vision field); }++ \text {, changes were occasionally observed in the samples of } \\
\text { all the animals of the studied group (average, } 8 \text { to } 10 \text { changes per vision field); }+++ \text {, } \\
\text { changes were often observed in the samples of all the animals of the studied group ( }>20 \\
\text { changes per vision field). }\end{array}$} \\
\hline
\end{tabular}

that the protective effects of a lactobacillus against acute cadmium toxicity are related to its cadmium binding capacity. Second, previous studies have indicated that acute oral cadmium toxicity causes atony and decreases peristalsis in the intestinal tract, which in turn induces constipation and a delay of cadmium excretion via feces $(26,34)$. Our study shows an amelioration of constipation by CCFM8610 treatment, especially in the living CCFM8610 therapy groups, which indicates that living CCFM8610 may improve the intestinal motility depressed by cadmium toxicity to increase the fecal excretion of cadmium. Third, intestinal cadmium absorption is associated with divalent metal transporter 1 , a protein that has a broad specificity favoring divalent metals such as $\mathrm{Ca}^{2+}, \mathrm{Fe}^{2+}$, and $\mathrm{Zn}^{2+}(35,36)$. In other words, there is a competitive relationship between the absorption of cadmium and that of divalent essential elements $(4,37,38)$. Interestingly, it is reported that living lactobacilli and bifidobacteria such as L. plantarum, L. rhamnosus, B. bifidum, and Bifidobacterium longum can improve the absorption and bioavailability of several essential elements like $\mathrm{Ca}, \mathrm{Mg}$, and Fe in both humans and animals (39-42). Therefore, although yet to be confirmed, it can be speculated that living CCFM8610 may have the capacity to increase the absorption of divalent essential elements and thus decrease the intestinal absorption of cadmium.

TABLE 5 Effects of L. plantarum CCFM8610 on cadmium-induced histopathological alterations in the kidney of mice ${ }^{a}$

\begin{tabular}{llll}
\hline & \multicolumn{2}{l}{ Score for the indicated symptom } \\
\cline { 2 - 4 } & $\begin{array}{l}\text { Loss of intact } \\
\text { tubules and } \\
\text { glomeruli }\end{array}$ & $\begin{array}{l}\text { Dilation in the } \\
\text { glomeruli }\end{array}$ & Tubular necrosis \\
Group & - & - & - \\
\hline Control (T) & + & + & - \\
Cd only (T) & - & + & - \\
Cd + living 8610 (T) & - & + & - \\
Cd + dead 8610 (T) & - & - & - \\
Control (P) & - & + & - \\
Cd only (P) & + & + & - \\
Cd + living 8610 (P) & - & + & - \\
Cd + dead 8610 (P) & - & - &
\end{tabular}

${ }^{a}$ The histopathological analysis was done with 10 mice in each group, except for 11 in the Cd-only (T) group, 12 in the Cd-only (P) group, and 9 in the $\mathrm{Cd}+$ dead $8610(\mathrm{P})$ group. T, therapy group; $\mathrm{P}$, prevention groups; 8610 , L. plantarum CCFM8610; - , no change was observed in the samples of all the animals of the studied group; + , changes were rarely observed in the samples of all the animals of the studied group (average, 1 to 2 changes per vision field). 

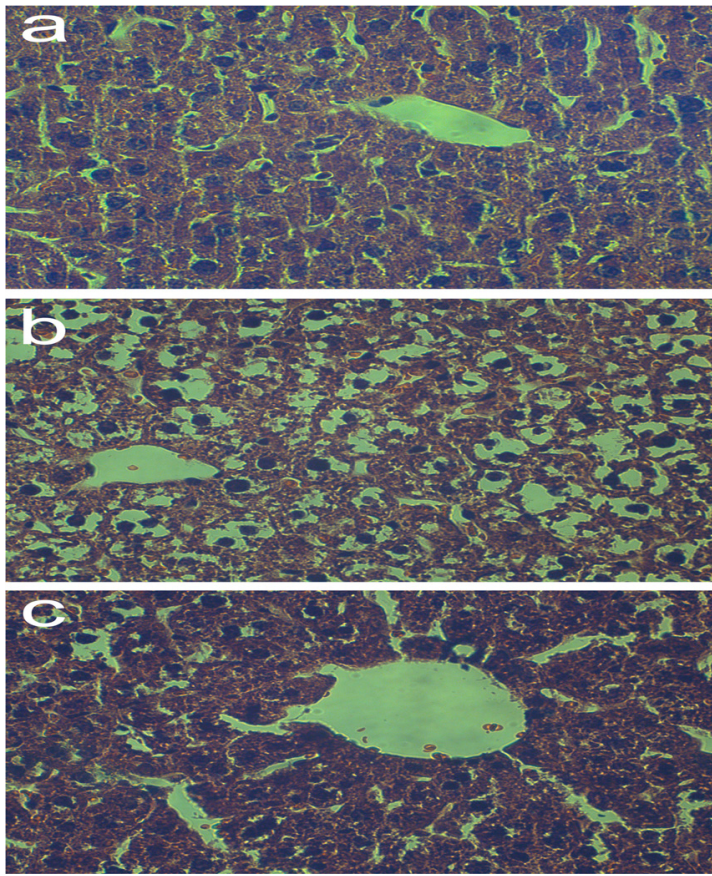

FIG 5 Representative photomicrographs of hepatic tissue of mice. (a) Hepatic tissue of mice in the control therapy group, with normal hepatic appearance; (b) hepatic tissue of mice in the Cd-only therapy group, with loss of intact liver plates, cytoplasmic vacuolization, pyknotic nuclei, chromatin condensation, and necrosis of hepatocytes; (c) hepatic tissue of mice in the Cd plus living CCFM8610 therapy group, with preserved hepatic appearance, alleviation of cytoplasmic vacuolization and chromatin condensation, and no necrosis of hepatocytes. H\&E staining was used. Magnifications, $\times 400$.

Oxidative stress is an important mechanism of cadmium toxicity; it includes increased lipid peroxidation and decreased activities of antioxidant enzymes. It was reported that oxidative stress can impair the cell membrane, thus leading to the necrosis of hepatocytes (43); this may be the reason for the hepatic damage observed in our histopathological studies. MDA is an end product and indicator of the lipid peroxidation process. GSH is thought to play a crucial role in the antioxidant defense system. Abnormal formation of ROS induced by cadmium exposure may consume GSH rapidly and significantly decrease GSH levels in both the liver and kidney (44). Consistent with these analyses, our results show significant increases in MDA levels and decreases in GSH levels in both the liver and kidney after acute cadmium exposure (Tables 2 and 3). The drastic increase of ROS may also exceed the antioxidative capacities of SOD and CAT, causing the exhaustion of these enzymes and a reduction in their activities (9). Consistent with several previous studies, our results have identified significant decreases of SOD and CAT activities in both liver and kidney after cadmium exposure $(16,45,46)$.

The decreased MDA levels and the increased GSH levels and SOD and CAT activities shown in Tables 2 and 3 demonstrate that CCFM8610 has marked abilities to protect the liver and kidney against cadmium-induced oxidative damage. However, it is still not clear whether such protections are simply downstream effects due to the initial intestinal cadmium sequestration or a direct protection related to the antioxidative abilities of CCFM8610, or even both. Actually, many lactobacilli have been reported to have antioxidative capacities, and they have been applied to the allevi-

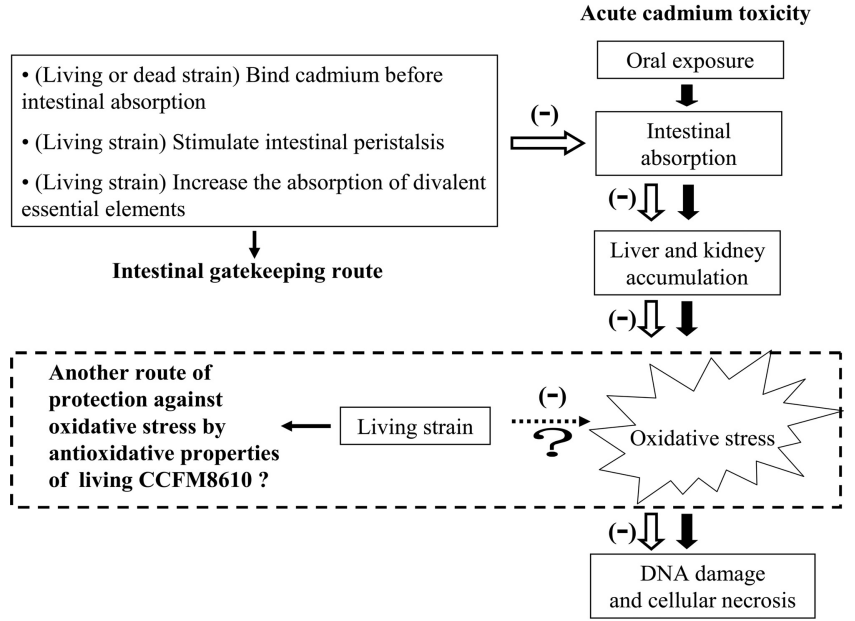

FIG 6 Intoxication processes induced by acute oral cadmium exposure and protective mechanisms of CCFM8610 against cadmium toxicity.

ation of oxidative stress induced by various dysfunctions $(47,48)$. Previous studies have reported that lactobacilli function as antioxidants by improving the lipid metabolism, increasing antioxidant enzyme activities, and inhibiting lipid peroxidation reactions $(49,50)$. Several studies have also indicated that some lactobacillus strains may have a complete GSH system, including synthesis, transport, uptake, and redox cycling $(51,52)$; this system makes them good protectors against oxidative stress. However, these mechanisms are effective only in living strains. On the basis of these analyses, the antioxidant abilities may be another mechanism through which living CCFM8610 alleviates cadmium toxicity, along with having the capacity to decrease intestinal cadmium absorption. A further study to investigate this potential mechanism is now in progress.

The differences between the mice in the prevention and therapy groups treated with both living and dead strains give insights into the protective mechanism of CCFM8610 against acute cadmium toxicity. Taking all effects of mortality, constipation, fecal cadmium excretion, tissue cadmium concentration, oxidative stress, and histopathological changes into consideration, living CCFM8610 treatment in the therapy groups offers the best protection against acute cadmium toxicity. The different effects between the prevention and therapy groups may be due to the higher level of CCFM8610 in the therapy groups than in the prevention groups, indicating that the intestinal colonization ability of CCFM8610 is not enough to provide the same biomass level as that which occurs when it is directly administered in therapy groups. The different protective effects between living and dead CCFM8610 could be explained by the possible models illustrated in Fig. 6. Briefly, treatment with a living strain may be capable of stimulating intestinal peristalsis, increasing the absorption of divalent essential elements, and causing direct alleviation of oxidative stress, whereas treatment with the dead strain may not be involved in these mechanisms. Therefore, although living and dead CCFM8610 strains have nearly the same cadmium binding ability in vitro, for animal experiments, more protective effects were found in the living strain treatment groups than in the dead strain treatment groups.

In conclusion, this study demonstrated that $L$. plantarum 
CCFM8610 has protective capacities against acute cadmium toxicity in mice. It is the first study to reveal the effects of a lactobacillus on decreasing intestinal cadmium absorption, reducing tissue cadmium accumulation, alleviating renal and hepatic oxidative stress, and ameliorating hepatic histopathological changes. The study also showed that living CCFM8610 administered after cadmium exposure is the most effective of all the treatments. These interesting results show that $L$. plantarum CCFM8610 could be used as a supplementary ingredient to provide a novel dietary therapeutic strategy against acute cadmium toxicity.

\section{ACKNOWLEDGMENTS}

This work was supported by the National Science Fund for Distinguished Young Scholars (no. 31125021), the National High Technology Research and Development Program of China (863 Program no. 2011AA100901 and 2011AA100902), the National Basic Research Program of China (973 Program no. 2012CB720802), the National Natural Science Foundation of China (no. 31200691), the Key Program of the National Natural Science Foundation of China (no. 20836003), the National Science and Technology Pillar Program (no. 2010C0070311), 111 Project B07029, and Fundamental Research Funds for the Central Universities (JUSRP111A31).

We declare that there are no conflicts of interest.

\section{REFERENCES}

1. Järup L, Åkesson A. 2009. Current status of cadmium as an environmental health problem. Toxicol. Appl. Pharmacol. 238:201-208.

2. WHO. 1992. Cadmium-environmental aspects. Environmental health criteria 135. WHO, Geneva, Switzerland.

3. Klaassen CD, Liu J, Diwan BA. 2009. Metallothionein protection of cadmium toxicity. Toxicol. Appl. Pharmacol. 238:215-220.

4. Goyer RA, Clarkson TW. 2001. Toxic effects of metals, p 825-826. In Klaassen C (ed), Casarett \& Doull's toxicology: the basic science of poisons, 5th ed. McGraw-Hill Health Professions Division, New York, NY.

5. Nordberg GF. 2009. Historical perspectives on cadmium toxicology. Toxicol. Appl. Pharmacol. 238:192-200.

6. Jihen EH, Fatima H, Nouha A, Baati T, Imed M, Abdelhamid K. 2010. Cadmium retention increase: a probable key mechanism of the protective effect of zinc on cadmium-induced toxicity in the kidney. Toxicol. Lett. 196:104-109.

7. Liu J, Qu W, Kadiiska MB. 2009. Role of oxidative stress in cadmium toxicity and carcinogenesis. Toxicol. Appl. Pharmacol. 238:209-214.

8. Ognjanović BI, Marković SD, Đorðević NZ, Trbojević IS, Štajn AŠ, Saičić ZS. 2010. Cadmium-induced lipid peroxidation and changes in antioxidant defense system in the rat testes: protective role of coenzyme Q10 and vitamin E. Reprod. Toxicol. 29:191-197.

9. Thijssen S, Cuypers A, Maringwa J, Smeets K, Horemans N, Lambrichts I, Van Kerkhove E. 2007. Low cadmium exposure triggers a biphasic oxidative stress response in mice kidneys. Toxicology 236:29-41.

10. Yan H, Carter CE, Xu C, Singh PK, Jones MM, Johnson JE, Dietrich MS. 1997. Cadmium-induced apoptosis in the urogenital organs of the male rat and its suppression by chelation. J. Toxicol. Environ. Health 52:149-168.

11. Kojima S, Sugimura Y, Hirukawa H, Kiyozumi M, Shimada H, Funakoshi T. 1992. Effects of dithiocarbamates on testicular toxicity in rats caused by acute exposure to cadmium. Toxicol. Appl. Pharmacol. 116:2429.

12. Tandon SK, Singh S, Prasad S, Khandekar K, Dwivedi VK, Chatterjee M, Mathur N. 2003. Reversal of cadmium induced oxidative stress by chelating agent, antioxidant or their combination in rat. Toxicol. Lett. 145:211-217.

13. Eybl V, Kotyzova D, Koutensky J. 2006. Comparative study of natural antioxidants-curcumin, resveratrol and melatonin - in cadmiuminduced oxidative damage in mice. Toxicology 225:150-156.

14. Bludovska M, Kotyzova D, Koutensky J, Eybl V. 1999. The influence of $\alpha$-lipoic acid on the toxicity of cadmium. Gen. Physiol. Biophys. 18:28-32.
15. Vicente-Sánchez C, Egido J, Sánchez-González PD, Pérez-Barriocanal F, López-Novoa JM, Morales AI. 2008. Effect of the flavonoid quercetin on cadmium-induced hepatotoxicity. Food Chem. Toxicol. 46:22792287.

16. Renugadevi J, Prabu SM. 2009. Naringenin protects against cadmiuminduced oxidative renal dysfunction in rats. Toxicology 256:128-134.

17. Yadav N, Dogra RKS, Khan MY, Khandelwal S. 2005. Prevention of acute cadmium toxicity by picroliv. Hum. Exp. Toxicol. 24:529-536.

18. Yadav N, Khandelwal S. 2008. Effect of picroliv on cadmium induced testicular damage in rat. Food Chem. Toxicol. 46:494-501.

19. Halttunen T, Collado MC, El-Nezami H, Meriluoto J, Salminen S. 2008. Combining strains of lactic acid bacteria may reduce their toxin and heavy metal removal efficiency from aqueous solution. Lett. Appl. Microbiol. 46:160-165.

20. Mrvcic J, Stanzer D, Bacun-Druzina V, Stehlik-Tomas V. 2009. Copper binding by lactic acid bacteria (LAB). Biosci. Microflora 28:1-6.

21. Kullisaar T, Songisepp E, Mikelsaar M, Zilmer K, Vihalemm T, Zilmer M. 2003. Antioxidative probiotic fermented goats' milk decreases oxidative stress-mediated atherogenicity in human subjects. Br. J. Nutr. 90: 449-456.

22. Forsyth CB, Farhadi A, Jakate SM, Tang Y, Shaikh M, Keshavarzian A. 2009. Lactobacillus GG treatment ameliorates alcohol-induced intestinal oxidative stress, gut leakiness, and liver injury in a rat model of alcoholic steatohepatitis. Alcohol 43:163-172.

23. Watterlot L, Rochat T, Sokol H, Cherbuy C, Bouloufa I, Lefèvre F, Gratadoux J-J, Honvo-Hueto E, Chilmonczyk S, Blugeon S. 2010. Intragastric administration of a superoxide dismutase-producing recombinant Lactobacillus casei BL23 strain attenuates DSS colitis in mice. Int. J. Food Microbiol. 144:35-41.

24. Monachese M, Burton JP, Reid G. 2012. Bioremediation and tolerance of humans to heavy metals through microbial processes: a potential role for probiotics? Appl. Environ. Microbiol. 78:6397-6404.

25. Aksu Z, Dönmez G. 2001. Comparison of copper(II) biosorptive properties of live and treated Candida sp. J. Environ. Sci. Health A Tox. Hazard Subst. Environ. Eng. 36:367-381.

26. Andersen O, Nielsen JB, Svendsen P. 1988. Oral cadmium chloride intoxication in mice: effects of dose on tissue damage, intestinal absorption and relative organ distribution. Toxicology 48:225-236.

27. Andersen O, Nielsen JB. 1988. Oral cadmium chloride intoxication in mice: effects of penicillamine, dimercaptosuccinic acid and related compounds. Pharmacol. Toxicol. 63:386-389.

28. Engström B, Norin H, Jawaid M, Ingman F. 1980. Influence of different Cd-EDTA complexes on distribution and toxicity of cadmium in mice after oral or parenteral administration. Acta Pharmacol. Toxicol. 46:219234.

29. Nordberg M, Nordberg G. 2000. Toxicological aspects of metallothionein. Cell. Mol. Biol. 46:451-463.

30. Klaassen CD, Liu J. 1997. Role of metallothionein in cadmium-induced hepatotoxicity and nephrotoxicity. Drug Metab. Rev. 29:79-102.

31. Nordberg M, Nordberg G. 1987. On the role of metallothionein in cadmium induced renal toxicity. Experientia Suppl. 52:669-675.

32. Paul D, Hoskins LC. 1972. Effect of oral lactobacillus feedings on fecal lactobacillus counts. Am. J. Clin. Nutr. 25:763-765.

33. Gratz S, Taubel M, Juvonen RO, Viluksela M, Turner PC, Mykkanen H, El-Nezami H. 2006. Lactobacillus rhamnosus strain GG modulates intestinal absorption, fecal excretion, and toxicity of aflatoxin B1 in rats. Appl. Environ. Microbiol. 72:7398-7400.

34. Engström B. 1981. Influence of chelating agents on toxicity and distribution of cadmium among proteins of mouse liver and kidney following oral or subcutaneous exposure. Acta Pharmacol. Toxicol. 48:108-117.

35. Park JD, Cherrington NJ, Klaassen CD. 2002. Intestinal absorption of cadmium is associated with divalent metal transporter 1 in rats. Toxicol. Sci. 68:288-294.

36. Bressler JP, Olivi L, Cheong JAEH, Kim Y, Bannona D. 2004. Divalent metal transporter 1 in lead and cadmium transport. Ann. N. Y. Acad. Sci. 1012:142-152.

37. Brzoska M, Moniuszko-Jakoniuk J. 2001. Interactions between cadmium and zinc in the organism. Food Chem. Toxicol. 39:967-980.

38. Ryu D-Y, Lee S-J, Park DW, Choi B-S, Klaassen CD, Park J-D. 2004. Dietary iron regulates intestinal cadmium absorption through iron transporters in rats. Toxicol. Lett. 152:19-25.

39. Pérez-Conesa D, López G, Abellán P, Ros G. 2006. Bioavailability of calcium, magnesium and phosphorus in rats fed probiotic, prebiotic and 
synbiotic powder follow-up infant formulas and their effect on physiological and nutritional parameters. J. Sci. Food Agric. 86:2327-2336.

40. Klobukowski J, Modzelewska-Kapitula M, Kornacki K. 2009. Calcium bioavailability from diets based on white cheese containing probiotics or synbiotics in short-time study in rats. Pak. J. Nutr. 8:933-936.

41. Kruger MC, Fear A, Chua W-H, Plimmer GG, Schollum LM. 2009. The effect of Lactobacillus rhamnosus HN001 on mineral absorption and bone health in growing male and ovariectomised female rats. Dairy Sci. Technol. 89:219-231.

42. Scholz-Ahrens KE, Ade P, Marten B, Weber P, Timm W, Avarsigmail Y, Glüer CC, Schrezenmeir J. 2007. Prebiotics, probiotics, and synbiotics affect mineral absorption, bone mineral content, and bone structure. J. Nutr. 137:838S-846S.

43. Tzirogiannis KN, Panoutsopoulos GI, Demonakou MD, Hereti RI, Alexandropoulou KN, Basayannis AC, Mykoniatis MG. 2003. Timecourse of cadmium-induced acute hepatotoxicity in the rat liver: the role of apoptosis. Arch. Toxicol. 77:694-701.

44. Bagchi D, Bagchi M, Hassoun E, Stohs S. 1996. Cadmium-induced excretion of urinary lipid metabolites, DNA damage, glutathione depletion, and hepatic lipid peroxidation in Sprague-Dawley rats. Biol. Trace Elem. Res. 52:143-154.

45. Fouad AA, Qureshi HA, Yacoubi MT, Al-Melhim WN. 2009. Protective role of carnosine in mice with cadmium-induced acute hepatotoxicity. Food Chem. Toxicol. 47:2863-2870.
46. Yalin S, Comelekoglu U, Bagis S, Sahin NO, Ogenler O, Hatungil R. 2006. Acute effect of single-dose cadmium treatment on lipid peroxidation and antioxidant enzymes in ovariectomized rats. Ecotoxicol. Environ. Saf. 65:140-144.

47. Sharma S, Chaturvedi J, Chaudhari BP, Singh RL, Kakkar P. 2012. Probiotic Enterococcus lactis IITRHR1 protects against acetaminopheninduced hepatotoxicity. Nutrition 28:173-181.

48. Farag I, Abdel-Aziz K, Nada S, Tawfek N, Farouk T, Darwish H. 2010. Modulation of ochratoxin-induced oxidative stress, genotoxicity and spermatotoxic alterations by Lactobacillus rhamnosus GG in male albino mice. J. Am. Sci. 6:575-587.

49. Zhang Y, Du R, Wang L, Zhang H. 2010. The antioxidative effects of probiotic Lactobacillus casei Zhang on the hyperlipidemic rats. Eur. Food Res. Technol. 231:151-158.

50. Güven A, Gülmez M. 2003. The effect of kefir on the activities of GSH-Px, GST, CAT, GSH and LPO levels in carbon tetrachloride-induced mice tissues. J. Vet. Med. B 50:412-416.

51. Kullisaar T, Songisepp E, Aunapuu M, Kilk K, Arend A, Mikelsaar M, Rehema A, Zilmer M. 2010. Complete glutathione system in probiotic Lactobacillus fermentum ME-3. Appl. Biochem. Microbiol. 46:481-486.

52. Mikelsaar M, Zilmer M. 2009. Lactobacillus fermentum ME-3-an antimicrobial and antioxidative probiotic. Microb. Ecol. Health Dis. 21:1-27. 